\title{
Exploring the "Intensity Fading" Phenomenon in the Study of Noncovalent Interactions by MALDI-TOF Mass Spectrometry
}

\author{
Oscar Yanes* and Francesc X. Aviles \\ Institut de Biotecnologia i de Biomedicina, and Departament de Bioquimica, Universitat Autònoma \\ de Barcelona, Barcelona, Spain.
}

\author{
Peter Roepstorff and Thomas J. D. Jørgensen \\ Department of Biochemistry and Molecular Biology, University of Southern Denmark, Odense, Denmark
}

The difficulties to detect intact noncovalent complexes involving proteins and peptides by MALDI-TOF mass spectrometry have hindered a widespread use of this approach. Recently, "intensity fading MS" has been presented as an alternative strategy to detect noncovalent interactions in solution, in which a reduction in the relative signal intensity of low molecular mass binding partners (i.e., protease inhibitors) can be observed when their target protein (i.e., protease) is added to the sample. Here we have performed a systematic study to explore how various experimental conditions affect the intensity fading phenomenon, as well as a comparison with the strategy based on the direct detection of intact complexes by MALDI MS. For this purpose, the study is focused on two different protease-inhibitor complexes naturally occurring in solution, together with a heterogeneous mixture of nonbinding molecules derived from a biological extract, to examine the specificity of the approach, i.e., those of carboxypeptidase A (CPA) bound to potato carboxypeptidase inhibitor (PCI) and of trypsin bound to bovine pancreatic trypsin inhibitor (BPTI). Our results show that the intensity fading phenomenon occurs when the binding assay is carried out in the sub- $\mu \mathrm{M}$ range and the interacting partners are present in complex mixtures of nonbinding compounds. Thus, at these experimental conditions, the specific inhibitor-protease interaction causes a selective reduction in the relative abundance of the inhibitor. Interestingly, we could not detect any gaseous noncovalent inhibitor-protease ions at these conditions, presumably due to the lower highmass sensitivity of MCP detectors. (J Am Soc Mass Spectrom 2007, 18, 359-367) (c) 2007 American Society for Mass Spectrometry

$\mathrm{T}$ he capacity of matrix-assisted laser desorption ionization time-of-flight mass spectrometry (MALDI-TOF MS) to detect intact noncovalent biomolecular complexes was demonstrated by Karas and Hillenkamp and their coworkers only a few years after they developed MALDI [1, 2], however, it has not found widespread use up to now.

Several major effects have been described to result in nonnative conditions for the noncovalent complexes: MALDI matrix [3-5], sample preparation [4, 6, 7], crystal morphology $[4,8,9], \mathrm{pH}$ of the solution [6, $10-12]$, organic solvent $[7,8]$, ionic strength $[13,14]$, matrix/analyte ratio $[15,16]$, speed of solvent evaporation [4], and sample concentration [9, 15]. The effect of some instrumental parameters in the detection of com-

Published online November 9, 2006

Address reprint requests to Dr. F. X. Avilés, Institut de Biotecnologia i de Biomedicina, and Departament de Bioquimica, Universitat Autònoma de Barcelona, 08193 Bellaterra (Barcelona), Spain E-mail: FrancescXavier.Aviles@uab.es, and to Thomas J. D. Jørgensen, e-mail: tjdj@bmb.sdu.dk

* Also at the Department of Biochemistry and Molecular Biology, University of Southern Denmark. plexes has also been studied; extraction delay time, positive/negative ion mode, linear/reflector and acceleration mode were found to be of minor importance [7, 17], whereas laser pulse energy $[8,17,18]$ and the number of laser shots (i.e., "first shot phenomenon") [4, $8,13,19,20]$ was reported to be a decisive factor in a number of cases.

Also, analyses by electrospray ionization (ESI) [21] are not carried out at physiological conditions as only solutions of very low ionic strength can be analyzed. However, ESI generates "colder" ions than MALDI and it keeps the sample in aqueous "biological" environment before ionization. For these reasons, ESI has been used in numerous studies to detect noncovalent complexes [22].

Relatively few cases have been reported where specific intact noncovalent complexes were successfully observed with MALDI. Besides the frequent dissociation of noncovalent complexes due to the experimental conditions employed, a further complication for their study by MALDI MS is the presence of nonspecific aggregates, i.e., "cluster ions" [23, 24]. Thus, the speci- 
ficity of binding should be always verified by competitive and comparative assays after the addition of known ligands and nonbinding molecules. Following these control experiments, the interaction is confirmed when no cluster ions are observed or when the "specific" complex is far more abundant than "nonspecific" aggregates.

Within this context, one of our groups recently introduced an alternative strategy to detect the presence of noncovalent complexes in solution by MALDI MS [25].é Withé thisé strategy,éaé reductionéiné theérelative abundance of peptide ligands, visualized as a reduction of their relative intensity in the mass spectra, can be observed when their receptor protein is added to the MALDI sample; accordingly, we named this approach intensityé fadingé(IF-)é MALDI-TOFé MSé [25].é Thiséis equivalent to immunological procedures to identify epitopic peptides by their specific removal by antibodiesé[26,é27].éWeéhaveéextendedéitétoéaéwideérangeéof biological interactions (i.e., protein-protein, proteinnucleicécid,éandéprotein-organicécompounds)đ25]énd, more recently, as a promising approach to screen ligands in heterogeneous biological extracts (i.e., proteaseêinhibitors)é[28,é29].

However, no systematic study of the influence of various experimental conditions on the "intensity fading" phenomenon has been conducted until now. With this aim, here we report a study to (1) investigate how various experimental conditions and instrumental parameters affect the "intensity fading" phenomenon, and (2) to elucidate if "intensity fading MS" approach is a truly advantageous strategy by comparison with the direct detection of intact noncovalent complexes by MALDI TOF MS. For this purpose, we have selected the noncovalent complexes formed between two different enzymes of intermediate size and two proteic inhibitors (representative of small protein and peptide ligands), all of them well characterized: the pairs bovine carboxypeptidase A (CPA)/potato carboxypeptidase inhibitoré(PCI)écomplexé[30]éandétrypsin/bovineépancreaticétrypsinéinhibitoré(BPTI)écomplexé[31].éWeéhave explored the "fading" behavior of these protease inhibitors (in the low mass range) interacting with the enzymes as well as the observation of the entire specific complex (in the high mass range), with several MALDI matrices (in the presence or absence of ammonium salts). Various sample preparation procedures yielding different crystal morphologies were also investigated.

\section{Experimental}

\section{Materials}

The MALDI matrices sinapic acid (SIN), 6-aza-2-thiothyamine (ATT), 2,6-dihydroxyacetophenone (DHAP), $\alpha$-cyano-4-hydroxycinnamic acid (CHCA), 2-(4-hydroxyphenylazo)benzoic acid (HABA), and the structural isomers 2,5- and 2,6-dihydroxybenzoic acid (2,5and 2,6-DHB) were purchased from Sigma-Aldrich (St.
Louis, MO) and were used without further purification. Ammonium acetate, ammonium citrate, and ammonium dihydrogen phosphate were purchased from Fluka (Buchs, Switzerland). Universal $\mathrm{pH}$ indicator strips, $\mathrm{pH} 0.0$ to $2.5,2.5$ to 4.5 , and 4.0 to 7.0 were purchased from Merck KGaA (Darmstadt, Germany). Trypsin (modified/sequencing grade) was purchased from Promega (Madison, WI). Carboxypeptidase A modified from bovine pancreas was purchased from Boehringer Mannheim (Ingelheim, Germany). The solvents acetonitrile $(\mathrm{ACN})$ and acetone were analytical or LiChrosolv grade (Merck, Darmstadt, Germany). Leech carboxypeptidase inhibitor (LCI), potato carboxypeptidase inhibitor (PCI) were obtained as previously describedê[32,é33].éAprotininé(BPTI)ẻbovineéwasérecombinant, expressed in Nicotiana (tobacco) (Sigma-Aldrich, St. Louis, MO). All aqueous solutions were prepared using Milli-Q water filtered with a $0.2 \mu \mathrm{m}$ membrane filter (Millipore, Bedford, MA). Extract from Hirudo medicinalis was supplied by the group of Professors $\mathrm{H}$. Fritz and C. Sommerhoff (Chirurgischen Klinik Innenstadt, Ludwig-Maximilians-Universitat, Munich, Germany). Hirudo medicinalis extract was dissolved in deionized water at a concentration of $20 \mathrm{mg} / \mathrm{mL}$. These solutions were centrifuged at $8000 \mathrm{~g}$ for $10 \mathrm{~min}$, and the supernatant was processed by size-exclusion chromatography Superdex Peptide HR 10/30 (Amersham Biosciences, Barcelona, Spain). The chromogenic substrate $\mathrm{N}$-(4-methoxyphenylazoformyl)-Phe-OH was obtained from Bachem (Weil am Rhein, Germany).

\section{Sample Preparation}

Lyophilized samples of LCI, PCI, Aprotinin, and CPA were dissolved in $20 \mathrm{mM}$ ammonium acetate at the desired molar concentration. Trypsin was dissolved in Milli-Q water at the desired molar concentration. The size-exclusion chromatography fraction of Hirudo medicinalis (essentially enriched with proteins in the range of 3 to $5 \mathrm{kDa}$ ) was lyophilized and dissolved in Milli-Q water. Possible inhibitory activity of the selected fraction was determined by measuring the inhibition of the hydrolysis of the chromogenic substrate N-(4-methoxyphenylazoformyl)-Phe-OH by carboxypeptidase type A at $350 \mathrm{~nm}$.

Nonbinding control samples were diluted to yield ion abundances similar to that of the protease inhibitor assayed in parallel; $0.5 \mu \mathrm{L}$ of each solution (i.e., protease inhibitor, nonbinding molecules, and protease or ammonium salt) were mixed and incubated for $3 \mathrm{~min}$ at room temperature. (1) For the dried-droplet sample preparation method, the following solutions were prepared: $10 \mathrm{mg} / \mathrm{mL}$ SIN, ATT, $\alpha$-CHCA, 2,5-DHB, DHAP, and $2 \mathrm{mg} / \mathrm{mL} \mathrm{HABA}$, in $\mathrm{ACN}$ mixed with either water $20 \mathrm{mM}$ ammonium acetate, $20 \mathrm{mM}$ ammonium citrate, or $20 \mathrm{mM}$ ammonium dihydrogen phosphate 1:4 (vol/ vol). For the MALDI analysis, 1.5 to $2 \mu \mathrm{L}$ of sample and 3 to $4 \mu \mathrm{L}$ of matrix solution were mixed into a $0.5 \mathrm{~mL}$ tube and $0.5 \mu \mathrm{L}$ of this mixture was deposited on a 
Table 1. Intensity fading assays for protease inhibitors (PCI, BPTI) and detection of the intact complexes in presence of their target proteases (CPA, trypsin)

\begin{tabular}{|c|c|c|c|}
\hline \multirow[b]{2}{*}{ MALDI matrix ${ }^{a}$} & \multicolumn{2}{|r|}{ CPA-PCl interaction } & \multirow{2}{*}{$\begin{array}{c}\text { Trypsin-BPTI } \\
\text { interaction }\end{array}$} \\
\hline & $\begin{array}{l}\text { Intensity fading } \\
\text { of } \mathrm{PCl}^{\mathrm{b}}\end{array}$ & $\begin{array}{l}\text { Detection of the intact non-covalent } \\
\text { complex }\end{array}$ & \\
\hline SIN (dried droplet) & + & + & + \\
\hline SIN (thin layer) & - & nt & nt \\
\hline$\alpha$-CHCA (dried droplet) & + & + & + \\
\hline$\alpha$-CHCA (thin layer) & - & - & nt \\
\hline DHAP (dried droplet) & + & + & + \\
\hline ATT (dried droplet, large crystals) & - & - & $+1-$ \\
\hline ATT (dried droplet, micro crystals) & + & + & $+/-$ \\
\hline 2,5-DHB (dried droplet) & - & - & $+/-$ \\
\hline 2,6-DHB (thin layer) & - & - & nt \\
\hline HABA (dried droplet) & + & + & + \\
\hline
\end{tabular}

asIN, sinapic acid; $\alpha$-CHCA, $\alpha$-cyano-4-hydroxycinnamic acid; DHAP, 2,6-dihydroxyacetophenone; ATT, 6-aza-2-thiothyamine; HABA, 2-(4-Hydroxyphenylazo)benzoic acid; 2,5-DHB and 2,6-DHB, 2,5- and 2,6-dihydroxybenzoic acid.

Intensity fading MS assays in a heterogeneous mixture of non-binding molecules. The relative intensity of protease inhibitor was measured in the presence or absence of protease. + indicates that the relative abundance of inhibitor decreased by at least a factor of 10 in the presence of protease; - indicates no significant decrease in the relative abundance of inhibitor in the presence of protease. The heterogeneous mixture consisted of more than 50 nonbinding molecules obtained from a leech extract.

'Direct detection of the intact noncovalent complex between protease and inhibitor. The concentration of the interacting proteins was $\sim 15$ - to 20 -fold increased with respect to that used for intensity fading experiments. Results are indicated without non-binding molecules in the mixture. + indicates a 2-fold or higher relative abundance of the protease-inhibitor complex than that of the non-specific cluster ions formed by homo-aggregates of protease or inhibitor; - indicates the absence of protease-inhibitor complex or a similar relative abundance of the protease-inhibitor complex and nonspecific cluster ions formed by homo-aggregates of inhibitor or protease; $+/-$ indicates ambiguous results due to a large shot-to-shot variability; nt means not tested.

stainless steel target and dried at room-temperature. (2) Thin-layer preparation: SIN, $\alpha$-CHCA and 2,5-DHB were dissolved in acetone at a concentration of 20 $\mathrm{mg} / \mathrm{mL} ; 2,6-\mathrm{DHB}$ was dissolved in acetone at a concentration of $100 \mathrm{mg} / \mathrm{mL}$. A $5 \mu \mathrm{L}$ aliquot of the matrix solution was spotted onto the target. A thin microcrystalline layer of matrix remained after fast evaporation of solvent; $0.5 \mu \mathrm{L}$ of the sample solution was deposited onto the thin matrix layer. After solvent evaporation at room temperature, the sample was washed as follows: 2 $\mu \mathrm{L}$ of Milli $\mathrm{Q}$ water were added on the sample and removed after a few seconds.

\section{MALDI-TOF Mass Spectrometry}

MALDI mass spectra were obtained using an Ultraflex MALDI-TOF mass spectrometer (Bruker Daltonics, Bremen, Germany) equipped with a $337 \mathrm{~nm}$ nitrogen laser, a gridless ion source, delayed-extraction (DE), and a 2 $\mathrm{GHz}$ digitizer. The instrument was operated in either reflector or linear mode by applying an accelerating voltage of $20 \mathrm{kV}$ except where otherwise stated. Delayed extraction was used and the delay time was set according to the molecular weight of the analytes (protease inhibitor or complex) to optimize resolution of its molecular ion. Mass spectra were acquired by averaging 300 to 600 shots (three different positions into each spot and 100 to 200 shots per position). Laser pulse energy was adjusted according to the various MALDI matrices. All subsequent mass spectra acquisitions were performed by applying the same laser fluence, including control mass spectrum and after the addition of target molecules.

\section{Results}

\section{"Intensity Fading MS" in Different Experimental} Conditions

A broad variety of experimental conditions were tested to study the specific binding of CPA to PCI, as determined by the "intensity fading MS" approach, when added to a heterogeneous mixture of more than 50 unknown nonbinding molecules derived from a natural extract of the leech Hirudo medicinalis. The only available information about these nonbinding molecules was the absence of carboxypeptidase A inhibitory activity (measured by classical spectrophotometric assays) (data not shown).

The relative intensity of PCI at $m / z 4298$, after the addition of its specific interacting partner, CPA $(\sim 34.200 \mathrm{Da})$, was studied using the matrices SIN, DHAP , $\alpha$-CHCA, ATT, 2,5-DHB, and HABA, following the "dried-droplet" MALDI sample preparation. On the other hand, the MALDI matrices 2,6-DHB, SIN, and $\alpha$-CHCA were used with the "thin-layer" sample preparation.éResultséareésummarizedéinéTableé1.é" Drieddroplet" sample preparation is clearly better than the "thin-layer" preparation for observing the "fading" phenomenon.éFigureélaéshowsétheémasséspectraéfor increasing amounts of CPA added to the complex mixture. A clear gradual fading of the relative intensity of PCI (0.6 pmol) is observed reaching almost a complete reduction of the signal when a 1:1 $\mathrm{M}$ ratio of CPA:PCI is employed. The other peaks are virtually unaffected by the addition of the protease. A similar fading phenomenon was observed using $\alpha$-CHCA as 

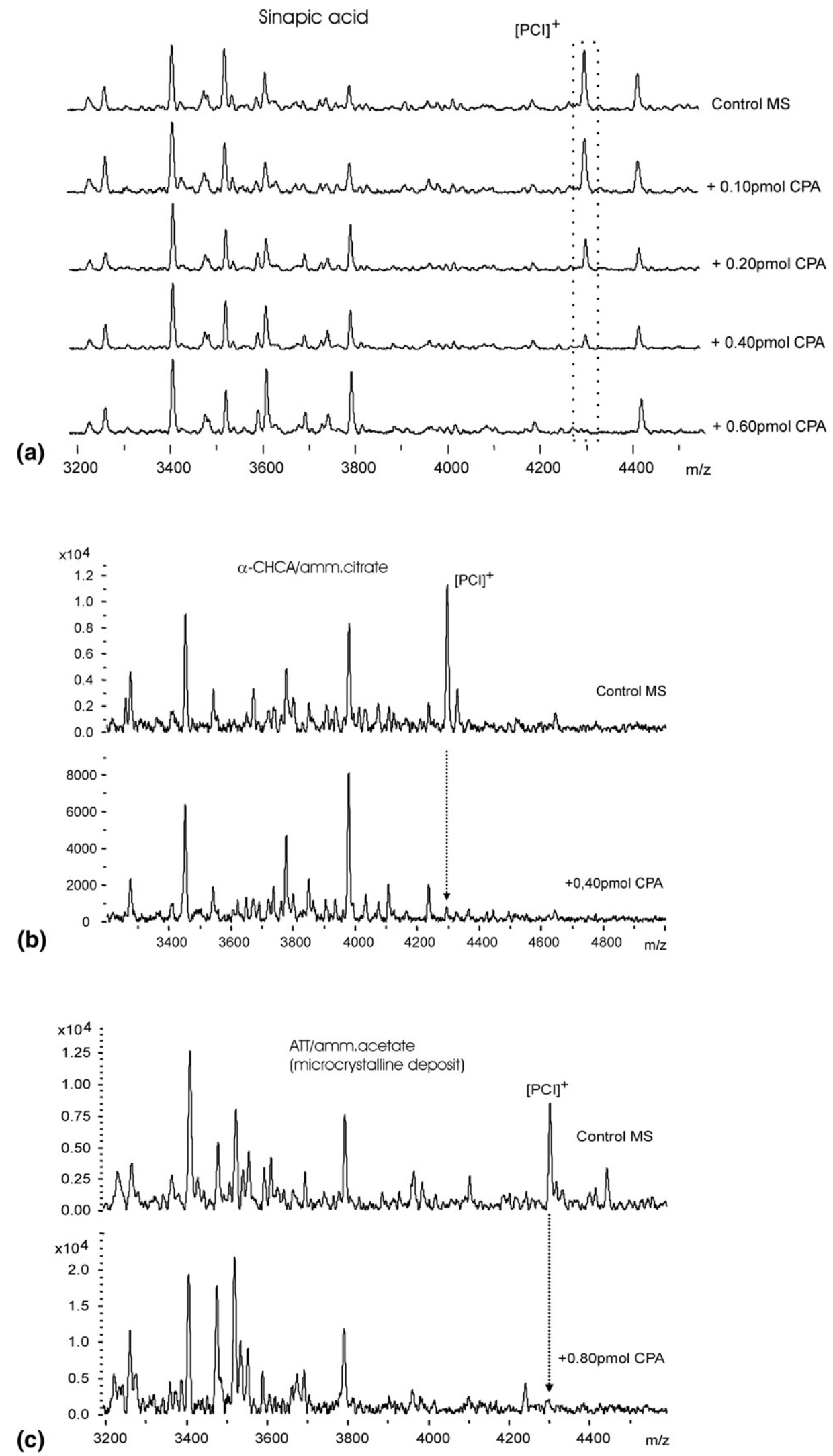

Figure 1. MALDI-TOF mass spectra of a complex mixture containing nonbinding peptides obtained from extract of leech and $0.6 \mathrm{pmol}$ of potato carboxypeptidase inhibitor (PCI) in the presence or absence of carboxypeptidase A (CPA). The peak corresponding to [PCI $]^{+}$at $\mathrm{m} / z 4296$ is indicated by dotted lines. Only the mass range displaying the $[\mathrm{PCI}]^{+}$peak and its adjacent peaks are shown. Mass spectra were obtained using the dried-droplet preparation method and (a) sinapic acid, (b) $\alpha$-cyano4-hydroxycinnamic acid (CHCA) with ammonium citrate, (c) 6-azathiothymine (ATT) with ammonium acetate, as MALDI matrices. 
Table 2. $\mathrm{pH}^{\mathrm{a}}$ values of the matrix solutions

\begin{tabular}{lcccc}
\hline MALDI matrices & 20\% ACN/water & $\begin{array}{c}20 \% \text { ACN/ 20mM } \\
\text { ammonium } \\
\text { citrate }\end{array}$ & $\begin{array}{c}20 \% \text { ACN/ 20mM } \\
\text { ammonium } \\
\text { acetate }\end{array}$ & $\begin{array}{c}20 \% \text { ACN/ 20mM } \\
\text { ammonium } \\
\text { dihydrogen } \\
\text { phosphate }\end{array}$ \\
\hline \hline SIN & 2.5 & 4 & 4 & 3.5 \\
$\alpha$-CHCA & $2-2.5$ & $3-3.5$ & 3.5 & 3.0 \\
DHAP & 4.0 & 5.0 & 5.5 & 4.5 \\
ATT & 3.5 & 4.5 & $4.5-5$ & 4.0 \\
2,5-DHB & 1.5 & 3.0 & 3.0 & 2.5 \\
HABA & $3.5-4$ & 5.0 & $5-5.5$ & 4.5 \\
\hline
\end{tabular}

${ }^{\mathrm{a}} \mathrm{pH}$ values were measured with universal $\mathrm{pH}$ indicator strips $(\mathrm{pH}$ ranges $0.0-2.5 ; 2.5-4.5 ; 4.0-7.0)$.

matrixé(Figureêlb).ênétheécaseéofétheêesséacidicêMALDI matrixé(seeéTableé2)éATT,étwoédifferentématrixécrystal morphologies were observed. At the rim of the sample spot, thin macrocrystalline long needles were prominent, whereas the center was covered by a homogeneous microcrystalline layer of matrix (particularly with ammonium acetate). Surprisingly, the relative signal intensity of PCI was not reduced in the presence of CPA when the macrocrystalline needles were analyzed (with and without ammonium salts) (data not shown). By contrast, a marked reduction of the relative signal intensity of PCI was detected in the microcrystalline layeré(Figureélc).éForétheélongéneedles,éaéhighéspot-tospot signal variability was observed; at some positions, the relative signal intensity of PCI was significantly reduced from the spectra within the first few laser shots. But, at increasing laser fluence or number of laser shots, the inhibitor was unaffected, i.e., having the same relative signal intensity as that of the control spectrum. Similar long needles were observed at the rim of the spot when the matrix 2,5-DHB was used. Also for this matrix, the relative signal intensity of PCI was unaffected by the addition of CPA, even in the presence of a 2-fold molar excess of the protease (data not shown). It should be noted that neither the specific CPA-PCI complex $(m / z \sim 38,500)$ nor the free CPA $(m / z \sim 34,200)$ were detected in these experiments at the corresponding mass range in the mass spectra, regardless of the matrix and the experimental conditions conceived.

The same experiments were performed using SIN, $\alpha$-CHCA, and 2,6-DHB as matrices and the "thin-layer" as sample preparation method. With these conditions, the addition of CPA did not affect the relative signal intensity of its natural ligand PCI (data not shown).

Variation of the laser fluence had no effect on the fading phenomenon. We did not observe an equivalent of the "first-shot phenomenon" for the "intensity fading MS" approach, i.e., the relative signal intensity of the ligand was reduced to the same extent after exposure to 200 subsequent laser shots on the same position of the spot (except for macrocrystalline structures of ATT). Switching from positive linear to positive reflectron mode had no influence on the observed fading.
Intensity Fading MS Versus Direct Detection of Intact Noncovalent Complexes by MALDI-TOF MS

From a simple mechanistic point of view, the signal fading of the protease inhibitor ion should be a direct consequence of the preservation and detection of the intact noncovalent complex formed between the target protease and its specific inhibitor. Therefore, both strategies should be equally affected by the same experimental conditions. However, our results indicate that this is not true and that analyte concentration plays a key role, affecting in a different way both strategies. The detection of the intact noncovalent complexes assayed in this work (CPA-PCI and trypsin-BPTI) could only be observed when the overall amount of the analytes were increased $\sim 15$ - to 20 fold with regard to those applied in the intensity fading experiments.

Detection of the intact CPA-PCI complex in the mass spectrum. The formation of the noncovalent complex between CPA and PCI was also tested using seven different matrices and two different MALDI sample preparation methods, i.e., "dried-droplet" and "thinlayer"émethod.éAsésummarizedênéTableél,étheécomplex was detected using SIN, $\alpha$-CHCA, DHAP, HABA as well as the microcrystalline surface of ATT, whereas no complex could be observed using either 2,5-DHB or the thinélongéneedleséoféATTé(Figureé2).

The specificity of the assay was investigated by adding another protease inhibitor (BPTI) with no affinity for CPA in solution, as a nonbinding control molecule. The preservation of the specific binding between CPA and PCI was strongly dependent upon the type of MALDI matrix. Only the CPA-PCI complex is observed withé SINé matrixé (Figureé 3a),é whereasé ATTé matrix results in the exclusive formation of the nonspecific complexébetweenéCPAéandéBPTIé(Figureé3b).êNoteéthat although we exclusively detected the specific CPA-PCI complex with SIN matrix, or the nonspecific CPA-BPTI with ATT matrix, there was no detectable fading of the $m / z$ ion corresponding to PCI or BPTI, respectively, in these experimental conditions. In the case of the DHAP 

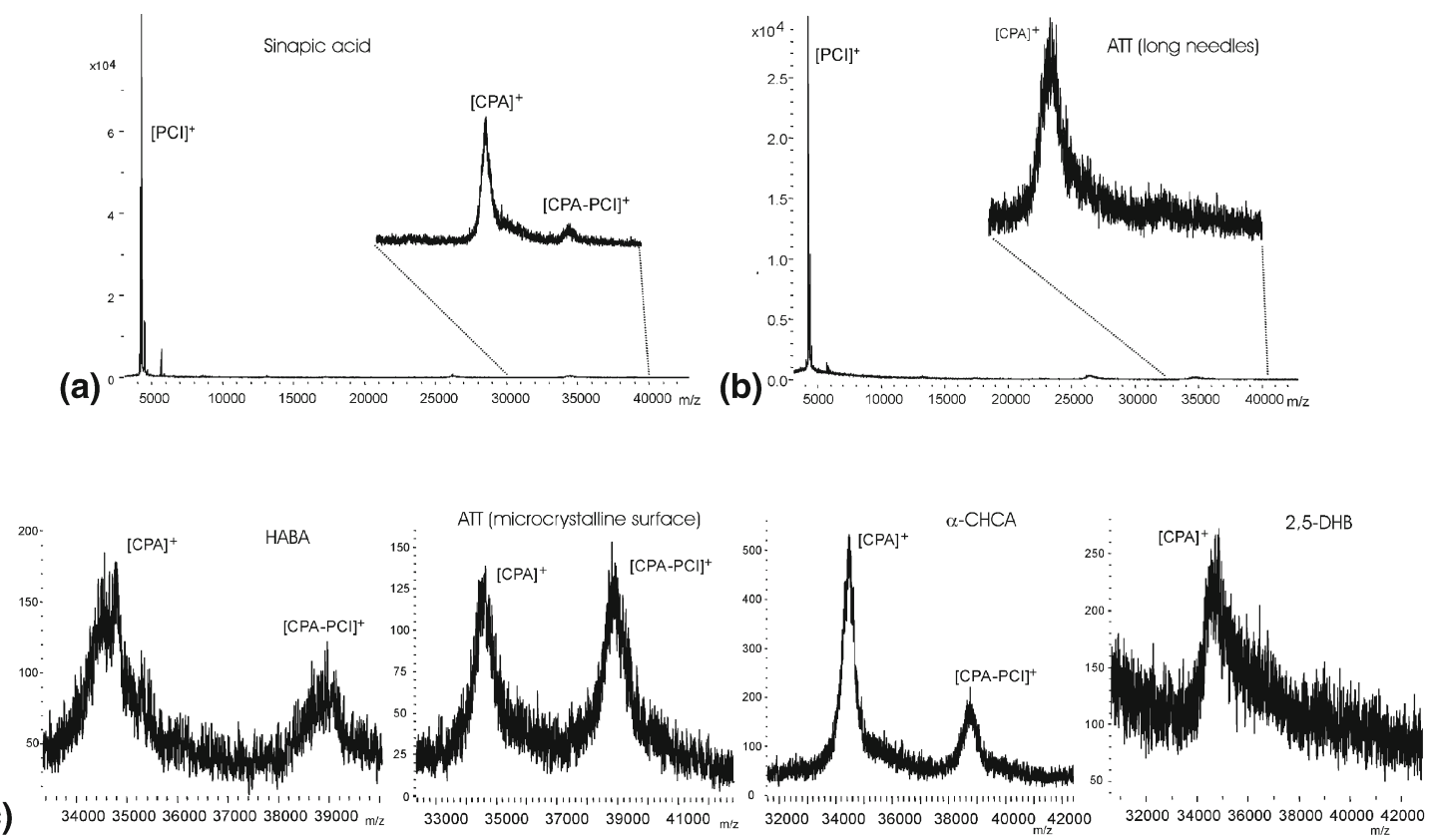

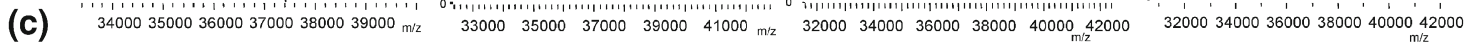

Figure 2. MALDI-TOF mass spectra of a sample containing $7 \mathrm{pmol}$ of PCI and $10 \mathrm{pmol}$ of CPA. Dried-droplet sample preparation with sinapic acid (a) and ATT (b) as matrices was used. Inset displays amplified regions corresponding to free CPA and the specific CPA-PCI complex. (c) MALDI-TOF mass spectra (same mixture and molar ratios as in (a) and (b) but shifted to the high $\mathrm{m} / \mathrm{z}$ region) showing free CPA and the specific complex CPA-PCI. HABA, ATT, $\alpha$-CHCA, and 2,5-DHB were used as matrices and dried-droplet as sample preparation.

matrix, neither the specific CPA-PCI complex nor the nonspecific one between CPA and BPTI could be detected; the mass spectrum was dominated by the three unligated compounds (data not shown). For HABA, the addition of BPTI led to reduction of the free CPA signal, thereby hampering the possibility of detecting any complex (data not shown). The effect of time-delayed extraction in linear and reflector mode was also studied, increasing from 120 to $500 \mathrm{~ns}$, showing insignificant changes in the spectra.

(a)
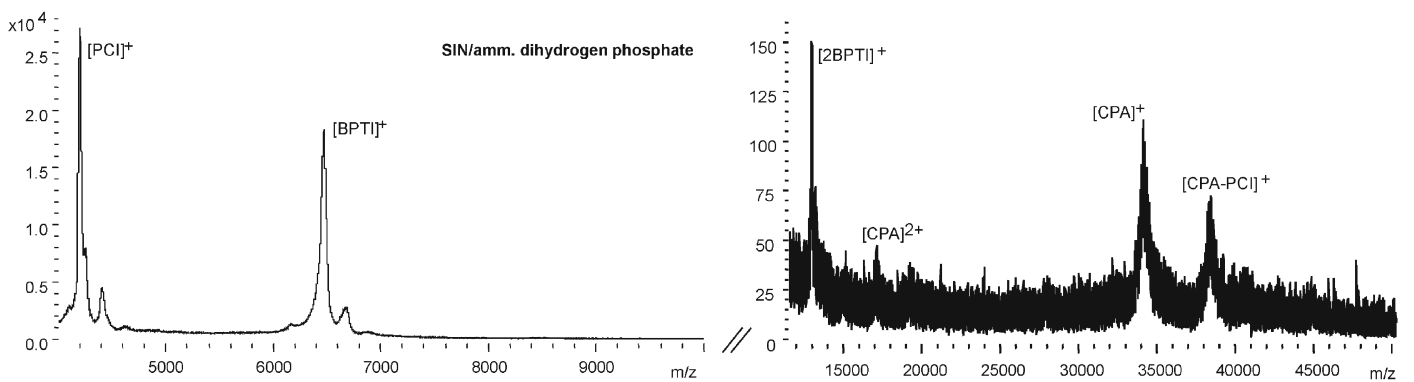

(b)
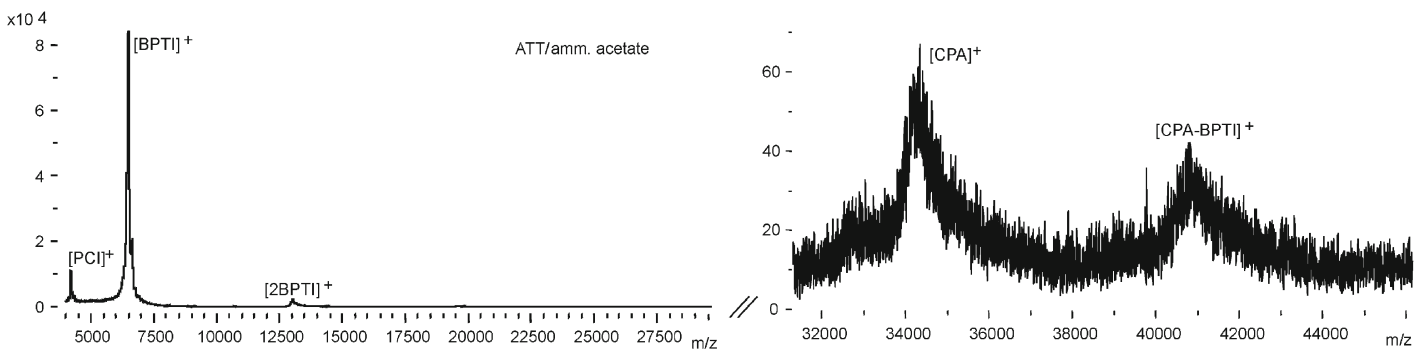

Figure 3. MALDI-TOF mass spectra of a sample containing equimolar amounts of PCI, BPTI, and CPA (20 pmol). Dried-droplet sample preparation with sinapic acid/ammonium dihydrogen phosphate (a) and ATT/ammonium acetate (b) as matrices was used. 
(a)
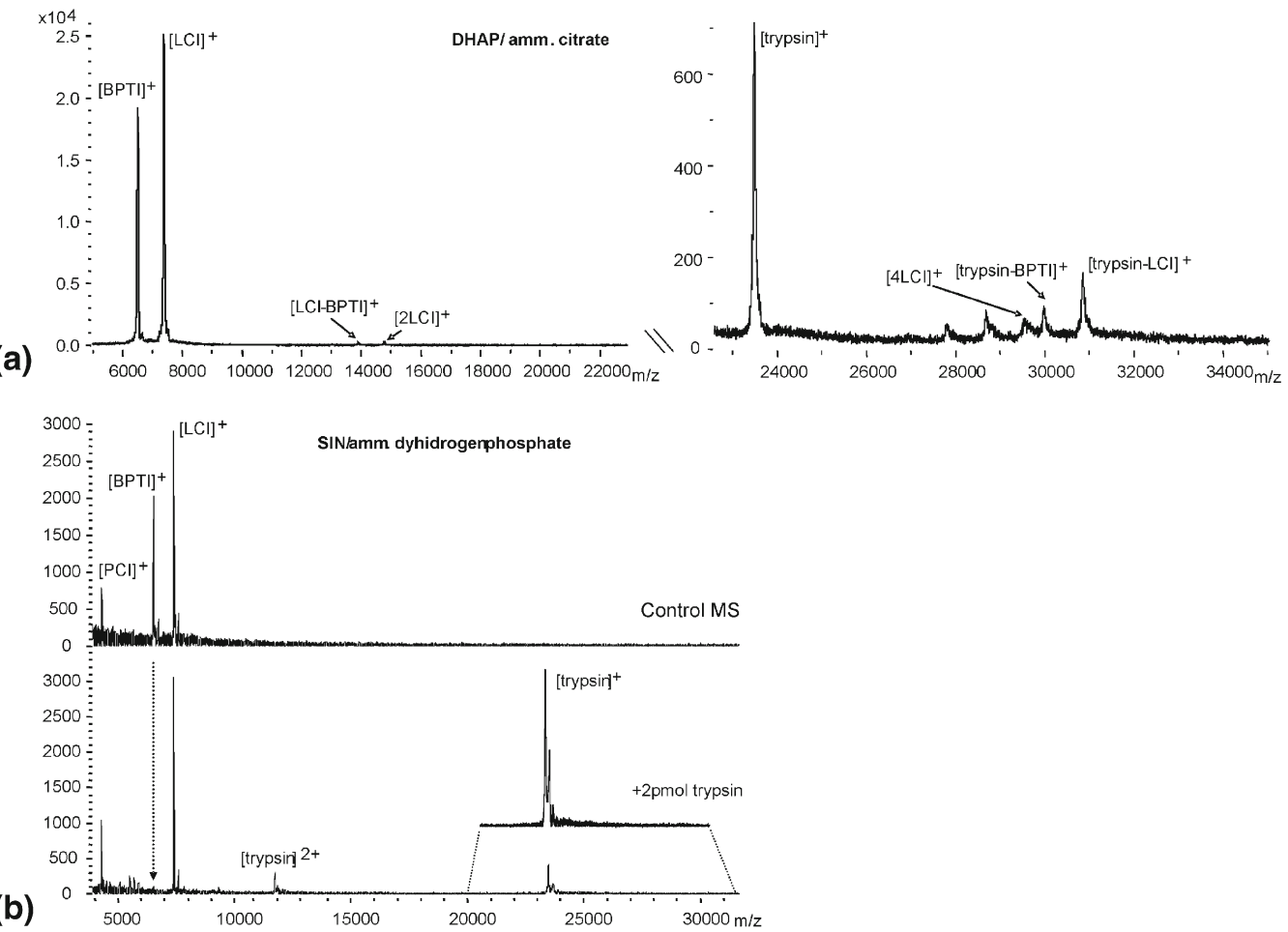

Figure 4. MALDI-TOF mass spectrum of a sample containing equimolar amounts of BPTI, LCI, and trypsin (15 pmol) (a). DHAP/ammonium citrate was used as matrix and dried-droplet as sample preparation. MALDI-TOF mass spectra of a simple mixture containing PCI and LCI as nonbinding control proteins and $0.8 \mathrm{pmol}$ of BPTI in the absence (top) and presence (bottom) of trypsin (b). SIN with ammonium dihydrogen phosphate was used as matrix and dried-droplet as sample preparation. Dotted arrow indicates the signal of the ligand.

Detection of the intact trypsin-BPTI complex in the mass spectrum. The noncovalent complex between trypsin and its specific natural inhibitor BPTI (1:1 M ratio) was also tested using the seven different matrices and "dried-droplet" method for MALDI sample preparation.éAsésummarizedênêTableêl,étheêntactécomplexéwas detected using SIN, DHAP, $\alpha$-CHCA, HABA (with and without ammonium salts) as matrices, whereas a high spatial signal variability was observed when ATT and 2,5-DHB were used.

A carboxypeptidase inhibitor, LCI, showing no affinity for trypsin in solution, was added to the mixture as nonbinding control molecule (1:1 $\mathrm{M}$ ratio). The nonspecific complex between trypsin and LCI was observed with all matrices. For DHAP, this unspecific complex was even more abundant than the naturally occurring trypsin-BPTI complexé(Figureé4a).éNoteéagain,étheéabsenceéofésignal fading for both the specific (BPTI) and nonspecific (LCI) inhibitors in presence of trypsin. This is in contrast with the intensity fading MS experiments performed in the sub-picomole range with the same analytes, plus another nonbindingémoleculeâikeePCIé(Figureétb).êHere,étheßBPTI ion specifically faded after the addition of its target protease, trypsin, whereas LCI and PCI signals are virtually unaffected. However, as stated also in the previous section for CPA-PCI interaction, we could not observe the intact trypsin-BPTI complex in its corresponding mass range of the mass spectrum.

\section{Discussion}

The "intensity fading MS" methodology has the ability to detect biomolecular interactions (i.e., protease-protease inhibitor in this work) in heterogeneous mixtures by a simple comparison of MALDI mass spectra. It is based on the phenomenon that signals of ligands can become strongly suppressed in MALDI mass spectra when they are engaged in complex formation with a receptor protein. In the present study, we have investigated the "intensity fading" phenomenon using a broad variety of MALDI matrices in combination with two preparation methods (dried-droplet and thin-layer) to explore and optimize the conditions to implement it as a screening methodology to detect biomolecular interactions (protease-protease inhibitor in our case) in heterogeneous biological mixtures, and verify whether it is a truly advantageous strategy compared with the direct detection of intact complexes by MALDI mass spectrometry.

Our results show that the "intensity fading" effect occurs under the specific experimental conditions characterized by the low concentration (sub-picomole) of the interacting partners and the complex mixture of internal nonbinding compounds, as well as the use of homogeneous crystal morphology obtained from drieddroplet sample preparation. For the model systems investigated in this work, $\mathrm{pH}$-values of matrix-analyte solutions is not a limitation, but may indeed become a 
restriction for systems more susceptible to $\mathrm{pH}$. Larger crystals of ATT and 2,5-DHB matrices as well as thinlayer sample preparations with $\alpha$-CHCA, 2,6-DHB, and SIN matrices prevented the fading of the protease inhibitors.

The absence of specific intact noncovalent complex ions (as well as the free enzyme) in the mass spectra in the "intensity fading" assays, is a consequence of the poor efficiency of detection of high molecular weight proteins, such as CPA or CPA-PCI complex, by MALDITOF MS instruments equipped with conventional microchanneléplateé(MCP)édetectorsé 34,é35].eßBesidesésensitivity problems, with MCP there is often the issue that when high molecular weight proteins are present in complex mixture of lower mass ions, the latter turn off channels of the detector by saturation during amplification. Results with improved detection efficiency for high mass ions by superconducting tunneling junction detectorsé(i.e.,écryodetectors)é[36]éconfirméthisépoint.

Given the complex experimental situation in MALDI, a nonoccurrence of the intensity fading does not necessarily mean that complexes are not formed. This is exemplified when the applied overall amount of proteins was increased by a factor of 15 to 20 with regard to those used in the intensity fading assays (i.e., sub-picomole range). We were able to detect the protease as well as the noncovalent complex formed with its specific inhibitor. It is worth mentioning that these analyte concentrations $(\sim 10$ to 30 $\mathrm{pmol} / \mu \mathrm{L}$ ) reproduce the experimental conditions reported in most of the previous studies of biomolecular interactionsénésolutionébyêMALDIế4,éé,ể,él7,é37].êHowever, when the specific trypsin-BPTI and CPA-PCI interaction was probed by adding inhibitors that are known not to interact with the protease in solution, we observed abundant nonspecific protease-inhibitor complexes (e.g., CPA-BPTIéandétrypsin-LCIécomplexeséinéFigureé3béand Figureúta,úrespectively)éndéggregatesénêheémassépectra (e.g.,étetramericéLClênéFigureéta).éThisémakeéclearéhhat,ét certain analyte concentrations, the formation of gaseous noncovalent complexes by MALDI does not originate exclusively from specific interactions that are preformed inésolution,éasérecentlyéalsoêndicatedê[17].

\section{Conclusions}

The "intensity fading MS" approach is attributable to an exclusive reduction in the relative intensity of peptide/ small protein ligands (i.e., protease inhibitors in our case) that can be observed when their target protein (i.e., protease) is added to the MALDI sample. The other peaks (i.e., nonbinding peptides, protein substrates) are virtually unaffected by the addition of the protease. Our results have shown that the "intensity fading" phenomenon shares some common disadvantages associated to the detection of intact noncovalent complexes by MALDI, such as sample preparation and choice of matrix.

However, the detection of the intact noncovalent complexes studied in this work by MALDI-TOF MS was only possible because of the relatively high amounts of interacting partners in the assays, which led to the formation of nonspecific complexes or aggregates (i.e., cluster ions). On the contrary, the "intensity fading MS" strategy is focused in the low mass range (below 10 to $15 \mathrm{kDa}$ ), profiting from the best sensitivity in this mass range of standard MALDI-TOF instruments equippedéwithémicrochanneléplateédetectorsé[35].éThis allowed us to work with rather highly complex mixtures of analytes in the sub-picomole range, which, we suggest, preserve at least partially the specific natural occurring bindings in solution and minimize the formation of nonspecific interactions in the gas phase.

Historically, any methodology to study noncovalent interactions in solution based on MALDI mass spectrometry has inevitably suffered from the physical and chemical processes associated to this technology. For this reason, "intensity fading MS" will not replace established affinity-based methodologies coupled to mass spectrometry such as surface plasmon resonance, cross-linking, or affinity purification among others. Even within the soft ionization techniques, ESI has been long recognized as the method of choice for studying noncovalenté complexesé [21].é However,é toé date,é we strongly believe that the real potential of MALDI mass spectrometry in the study of noncovalent interactions has been underestimated because of our limitation of a complete understanding of all processes underlying this technology. New experimental approaches not conceived until recent years like "intensity fading MS" or possibleémodificationsébasedéonétheésameéprincipleđ28, 36],ênfraredé(IR)êMALDIđ̣̊3,ê39], étmosphericépressure (AP)êMALDIÄ40,é41],êDIOS-MSê 42-44],éorénewégener-

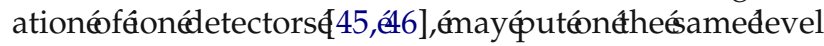
MALDI and ESI mass spectrometry in the field of noncovalent interactions.

\section{Acknowledgments}

The authors are indebted to Professors H. Fritz and C. Sommerhoff (Chirurgical Clinic, Munich, Germany) for providing them with the leech extract. This work was supported by grants GEN2003-20,642-C09-05 and BIO2004-05,879 (Ministerio de Ciencia y Tecnología, MCYT, Spain) and by the Centre de Referència en Biotecnologia (Generalitat de Catalunya, Spain). OY acknowledges a Marie Curie training site by the EU Commission.

\section{References}

1. Hillenkamp, F.; Karas, M.; Beavis, R. C.; Chait, B. T. Matrix-Assisted Laser Desorption Ionization Mass-Spectrometry of Biopolymers. Anal. Chem. 1991, 63, A1193-A1202.

2. Karas, M.; Bahr, U. Laser Desorption Ionization Mass-Spectrometry of Large Biomolecules. Trac-Trends in Anal. Chem. 1990, 9, 321-325.

3. Jespersen, S.; Niessen, W. M. A.; Tjaden, U. R.; van der Greef, J. Basic Matrices in the Analysis of Non-Covalent Complexes by MatrixAssisted Laser Desorption/Ionization Mass Spectrometry. J. Mass Spectrom. 1998, 33, 1088-1093.

4. Moniatte, M.; Lesieur, C; Vécsey-Semjén, B.; Buckley, J. T.; Pattus, F.; van der Goot, F. G.; Van Dorsselaer, A. Matrix-Assisted Laser Desorption-Ionization Time-of-Flight Mass Spectrometry in the Subunit Stoichmetry Study of High-Mass Non-Covalent Complexes. Int. J. Mass Spectrom. Ion Processes 1997, 169, 179-199.

5. Tang, X.; Callahan, J. H.; Zhou, P.; Vertes, A. Noncovalent ProteinOligonucleotide Interactions Monitored by Matrix-Assisted Laser De- 
sorption/Ionization Mass-Spectrometry. Anal Chem. 1995, 67, 4542-4548.

6. Schlosser, G.; Pocsfalvi, G.; Malorni, A.; Puerta, A.; de Frutos, M.; Vekey, K. Detection of Immune Complexes by Matrix-Assisted Laser Desorption/Ionization Mass Spectrometry. Rapid Commun. Mass Spectrom. 2003, 17, 2741-2747.

7. Zehl, M.; Allmaier, G. Investigation of Sample Preparation and Instrumental Parameters in the Matrix-Assisted Laser Desorption/Ionization Time-of-Flight Mass Spectrometry of Noncovalent Peptide/Peptide Complexes. Rapid Commun. Mass Spectrom. 2003, 17, 1931-1940.

8. Rosinke, B.; Strupat, K.; Hillenkamp, F.; Rosenbusch, J.; Dencher, N.; Krüger, U.; Galla, H. J. Matrix-Assisted Laser Desorption/Ionization Mass-Spectrometry (Maldi-MS) of Membrane-Proteins and Noncovalent Complexes. J. Mass Spectrom. 1995, 30, 1462-1468.

9. Zehl, M.; Allmaier, G. Ultraviolet Matrix-Assisted Laser Desorption/ Ionization Time-of-Flight Mass-Spectrometry of Intact Hemoglobin Complex from Whole Human Blood. Rapid Commun. Mass Spectrom. 2004, 18, 1932-1938.

10. Luo, S. Z.; Li, Y. M.; Qiang, W.; Zhao, Y. F.; Abe, H.; Nemoto, T.; Qin, X. R.; Nakanishi, H. Detection of Specific Noncovalent Interaction of Peptide with DNA by Maldi-TOF. J. Am. Soc. Mass Spectrom. 2004, 15, 28-31

11. Woods, A. S.; Huestis, M. A. A Study of Peptide-Peptide Interaction by Matrix-Assisted Laser Desorption/Ionization. J. Am. Soc. Mass Spectrom. 2001, 12, 88-96.

12. Woods, A. S.; Buchsbaum, J. C.; Worrall, T. A.; Berg, J. M.; Cotter, R. J. Matrix-Assisted Laser Desorption/Ionization of Noncolavently Bound Compounds. Anal. Chem. 1995, 67, 4462-4465.

13. Cohen, L. R. H.; Strupat, K.; Hillenkamp, F. Analysis of Quaternary Protein Ensembles by Matrix Assisted Laser Desorption/Ionization Mass Spectrometry. J. Am. Soc. Mass Spectrom. 1997, 8, 1046-1052.

14. Glocker, M. O.; Bauer, S. H.; Kast, J.; Volz, J.; Przybylski, M. Characterization of Specific Noncovalent Protein Complexes by UV MatrixAssisted Laser Desorption Ionization Mass Spectrometry. J. Mass Spectrom. 1996, 31, 1221-1227.

15. Farmer, T. B.; Caprioli, R. M. Determination of Protein-Protein Interactions by Matrix-Assisted Laser Desorption/Ionization Mass Spectrometry. J. Mass Spectrom. 1998, 33, 697-704

16. Moniatte, M.; van der Goot, F. G.; Buckley, J. T.; Pattus, F.; van Dorsselaer, A. Characterization of the Heptameric Pore-Forming Complex of the Aeromonas Toxin Aerolysin using Maldi-TOF Mass Spectrometry. FEBS Lett. 1996, 384, 269-272.

17. Zehl, M.; Allmaier, G. Instrumental Parameters in the Maldi-TOF Mass Spectrometric Analysis of Quaternary Protein Structures. Anal. Chem. 2005, 77, 103-110.

18. Perera, I. K.; Allwood, D.; Dyer, P. E.; Oldershaw, G. A. Formation of Homo and Hetero Multimeric Ions of Large Proteins in Matrix-Assisted UV Laser Desorption Ionization. J. Mass Spectrom. 1995, Suppl. S3-S12.

19. Gruic-Sovulj, I.; Ludemann, H. C.; Hillenkamp, F.; Kucan, I.; PeterKatalinic, J. Detection of Noncovalent tRNA-Aminoacyl-tRNA Synthetase Complexes by Matrix-Assisted Laser Desorption/Ionization Mass Spectrometry. J. Biol. Chem. 1997, 272, 32084-32091.

20. Vogl, T.; Roth, J.; Sorg, C.; Hillenkamp, F.; Strupat, K. Calcium-Induced Noncovalently Linked Tetramers of Mrp8 And Mrp14 Detected by Ultraviolet Matrix-Assisted Laser Desorption/Ionization Mass Spectrometry. J. Am. Soc. Mass Spectrom. 1999, 10, 1124-1130.

21. Benesch, J. L.; Robinson, C. V. Mass Spectrometry of Macromolecular Assemblies: Preservation and Dissociation. Curr. Opin. Struct. Biol. 2006, 16, 245-251.

22. Heck, A. J. R.; van den Heuvel, R. H. H. Investigation of Intact Protein Complexes by Mass Spectrometry. Mass Spectrom. Rev. 2004, 23, $368-$ 389.

23. Livadaris, V.; Blais, J. C.; Tabet, J. C. Formation of Non-Specific Protein Cluster Ions in Matrix-Assisted Laser Desorption/Ionization: Abundances and Dynamical Aspects. Eur. J. Mass Spectrom. 2000, 6, 409-413.

24. Perera, I. K.; Allwood, D.; Dyer, P. E.; Oldershaw, G. A. Observation of Mixed Molecular Cluster Ions in Matrix-Assisted UV Laser-Desorption Ionization of High-Mass Protein Mixtures. Int. J. Mass Spectrom. Ion Processes 1995, 145, L9.

25. Villanueva, J.; Yanes, O.; Querol, E.; Serrano, L.; Avilés, F. X. Identification of Protein Ligands in Complex Biological Samples using Inten-
sity-Fading Maldi-TOF Mass Spectrometry. Anal. Chem. 2003, 75, 3385-3395.

26. Kiselar, J. G.; Downard, K. M. Direct Identification of Protein Epitopes by Mass Spectrometry without Immobilization of Antibody and Isolation of Antibody-Peptide Complexes. Anal. Chem. 1999, 71, 1792-1801.

27. Kiselar, J. G.; Downard, K. M. Antigenic Surveillance of the Influenza Virus by Mass Spectrometry. Biochemistry 1999, 38, 14185-14191.

28. Yanes, O.; Villanueva, J.; Querol, E.; Avilés, F. X. Functional Screening of Serine Protease Inhibitors in the Medical Leech Hirudo medicinalis Monitored by Intensity Fading Maldi-TOF MS. Mol. Cell. Proteom. 2005, 4, 1602-1613.

29. Yanes, O.; Villanueva, J.; Querol, E.; Avilés, F. X. Intensity-fading Maldi-Tof MS: Novel Screening for Ligand Binding and Drug Discovery. Drug Discov. Today: TARGETS 2004, 3, 23-30.

30. Rees, D. C.; Lipscomb, W. N. Refined Crystal-Structure of the Potato Inhibitor Complex of Carboxypeptidase-A at 2.5-A Resolution. J. Mol. Biol. 1982, 160, 475-498.

31. Bode, W.; Huber, R. Natural Protein Proteinase-Inhibitors and Their Interaction with Proteinases. Eur. J. Biochem. 1992, 204, 433-451.

32. Marino-Buslje, C.; Venhudova, G.; Molina, M. A.; Oliva, B.; Jorba, X.; Canals, F.; Avilés, F. X.; Querol, E. Contribution of C-Tail Residues of Potato Carboxypeptidase Inhibitor to the Binding to Carboxypeptidase A - A Mutagenesis Analysis. Eur. J. Biochem. 2000, 267, 1502-1509.

33. Reverter, D.; Vendrell, J.; Canals, F.; Horstmann, J.; Avilés, F. X.; Fritz, H.; Sommerhoff, C. P. A Carboxypeptidase Inhibitor from the Medical Leech Hirudo medicinalis- Isolation, Sequence Analysis, cDNA Cloning, Recombinant Expression, and Characterization. J. Biol. Chem. 1998, 273, 32927-32933.

34. Frank, M.; Mears, C. A.; Labov, S. E.; Benner, W. H.; Horn, D.; Jaklevic, J. M.; Barfknecht, A. T. High-Efficiency Detection of 66000 Da Protein Molecules Using a Cryogenic Detector in a Matrix-Assisted Laser Desorption/Ionization Time-of-Flight Mass Spectrometer. Rapid Commun. Mass Spectrom. 1996, 10, 1946-1950.

35. Twerenbold, D.; Gerber, D.; Gritti, D.; Gonin, Y.; Netuschill, A.; Rossel, F.; Schenker, D.; Vuilleumier, J. L. Single Molecule Detector for Mass Spectrometry with Mass Independent Detection Efficiency. Proteomics 2001, 1, 66-69.

36. Yanes, O.; Nazabal, A.; Wenzel, R.; Zenobi, R.; Avilés, F. X. Detection of Noncovalent Complexes in Biological Samples by Intensity Fading and High-Mass Detection Maldi-TOF Mass Spectrometry. J. Proteom. Res. 2006, 5, 2711-2719.

37. Kiselar, J. G.; Downard, K. M. Preservation and Detection of Specific Antibody-Peptide Complexes by Matrix-Assisted Laser Desorption Ionization Mass Spectrometry. J. Am. Soc. Mass Spectrom. 2000, 11, 746-750.

38. Von Seggern, C. E.; Cotter, R. J. Fragmentation Studies of Noncovalent Sugar-Sugar Complexes by Infrared Atmospheric Pressure Maldi. J. Am. Soc. Mass Spectrom. 2003, 14, 1158-1165.

39. Von Seggern, C. E.; Cotter, R. J. Study of Peptide-Sugar Non-Covalent Complexes by Infrared Atmospheric Pressure Matrix-Assisted Laser Desorption/Ionization. J. Mass Spectrom. 2004, 39, 736-742.

40. Kellersberger, K. A.; Tan, P. V.; Laiko, V. V.; Doroshenko, V. M.; Fabris, D. Atmospheric Pressure Maldi-Fourier Transform Mass Spectrometry. Anal. Chem. 2004, 76, 3930-3934.

41. Laiko, V. V.; Taranenko, N. I.; Berkout, V. D.; Yakshin, M. A.; Prasad C. R.; Lee, H. S.; Doroshenko, V. M. Desorption/Ionization of Biomolecules from Aqueous Solutions at Atmospheric Pressure Using an Infrared Laser at 3 mu m.. J. Am. Soc. Mass Spectrom. 2002, 13, 354-361.

42. Deng, G.; Sanyal, G. Applications of Mass Spectrometry in Early Stages of Target Based Drug Discovery. J. Pharm. Biomed. Anal. 2006, 40, $528-538$.

43. Li, Q.; Ricardo, A.; Benner, S. A.; Winefordner, J. D.; Powell, D. H. Desorption/Ionization on Porous Silicon Mass Spectrometry Studies on Pentose-Borate Complexes. Anal. Chem. 2005, 77, 4503-4508.

44. Go, E. P.; Apon, J. V.; Luo, G.; Saghatelian, A.; Daniels, R. H.; Sahi, V. Dubrow, R.; Cravatt, B. F.; Vertes, A.; Siuzdak, G. Desorption/Ionization on Silicon Nanowires. Anal. Chem. 2005, 77, 1641-1646.

45. Nazabal, A.; Wenzel, R. J.; Zenobi, R. Immunoassays with Direct Mass Spectrometric Detection. Anal. Chem. 2006, 78, 3562-3570.

46. Wenzel, R. J.; Matter, U.; Schultheis, L.; Zenobi, R. Analysis of Megadalton Ions Using Cryodetection Maldi Time-of-Flight Mass Spectrometry. Anal. Chem. 2005, 77, 4329-4337. 